\title{
INCREASE OF FATIGUE RESISTANCE OF SHEET WELDED JOINTS OF ALUMINUM ALLOYS USING HIGH-FREQUENCY PEENING
}

\author{
V.V. KNYSH, I.N. KLOCHKOV, M.P. PASHULYA and S.I. MOTRUNICH \\ E.O. Paton Electric Welding Institute, NASU \\ 11 Bozhenko Str., 03680, Kiev, Ukraine. E-mail: office@paton.kiev.ua
}

\begin{abstract}
A work is dedicated to experimental investigation of dependencies of fatigue resistance of sheet $(\delta=2-3 \mathrm{~mm})$ welded joints of average and high strength aluminum alloys, which were produced using consumable-electrode pulsed-arc welding in inert gases (PMIG) as well as determination of efficiency of rise of their fatigue life through application of high-frequency mechanical peening (HFMP) by set parameters of strengthening. Efficient parameters of HFMP strengthening of sheet welded joints with the help of portable manual equipment USP-300 were determined based on measurement of microhardness, local geometry parameters of weld and angular residual lipping distortion. Influence of HFMP of zone of weld to base metal transition on measurement of stress concentration factor, welding residual stresses and structure of surface layer of butt joints of small thickness aluminum alloys was investigated. It is shown that increase of radius of weld to base metal transition and elimination of angular residual lipping distortion after HFMP treatment provides for 1.35-1.49 reduction of stress concentration factor in the joints. It is determined that life on the basis of testing $2 \cdot 10^{6}$ cycles of stress alternation for strengthened butt joints from D16T alloy shows 5 times rise, that for AMg6 alloy makes 4 times and 7 times for 6061-T6 alloy in comparison with initial as-welded condition. The recommendations are given on efficient HFMP strengthening of sheet welded joints for increase of their fatigue life and elimination of residual welding deformations. 15 Ref., 2 Tables, 11 Figures.
\end{abstract}

$\boldsymbol{K} \boldsymbol{e} \boldsymbol{y} \boldsymbol{w} \boldsymbol{o r d} \boldsymbol{s}:$ welded joint, high-cycle fatigue, alumi num alloys, fatigue life, high-frequency mechanical peening, consumable-electrode pulsed-arc welding, increase of fatigue resistance

Application of aluminum alloys as structural materials for manufacture of lightweight structures of different designation were determined by their physical, strength, technological and service properties [1-4]. Sheet welded structures from aluminum alloys with high strength and life indices are widely used in airspace industry, building, transport machine building etc. Significant experience was accumulated on application of aluminum alloys in the sheet welded structures of different designation. It showed that problem of providing of necessary life in operation under alternating load conditions is still relevant [4, 5]. Continuous work on improvement of consumables, implementation of new welding methods, application of different design solutions for structure assemblies and postweld heat treatment [57] is performed for solving this problem.

One of the perspective technologies allowing solving the questions of rise of welding efficiency of aluminum alloys with simultaneous reduction of their softening and improvement of welded joint quality is a high-production consumable- electrode pulsed arc-welding in inert gases (PMIG) $[6,8]$.

However, according to GOST, developed in the beginning of the 1970s and acting to present time, the process of consumable electrode welding of aluminum alloys can be applied only to the elements not less than $3 \mathrm{~mm}$ in butt joints and not less that $4 \mathrm{~mm}$ in lap joints. Current pulse power sources with synergic control of the process of consumable electrode welding allow expanding the thickness ranges of materials to be welded towards their lower values at well optimized modes of PMIG process.

However, in practice, development of quality small thickness joints using PMIG technology can be insufficient for providing of necessary fatigue life of the welded joint of structure elements from aluminum alloys of average and high strength without application of postweld strengthening treatment. One of the current high-productive technologies of strengthening of the welded metal structures is high-frequency mechanical peening (HFMP), which is based on application of ultrasonic energy for plastic surface deforming (PSD) of material [9]. It should be noted that data on application of HFMP for sheet $(\delta \leq 3 \mathrm{~mm})$ butt welded joints of aluminum alloys are absent in the world and domestic literature. 
Aim of the present work is experimental determination of effective parameters for technology of HFMP of sheet butt welded joints from aluminum AMg6, D16T and 6061-T6 alloys, produced using PMIG, and seting of the dependencies of rise of fatigue resistance and fatigue life of the strengthened joints.

Studied alloys of $2 \mathrm{~mm}$ thickness and welding wire Sv-AMg6 (GOST 7871-75) of $1.2 \mathrm{~mm} \mathrm{di-}$ ameter were used for optimizing of butt welding modes. First-grade argon was applied as a shielding gas. Automatic PMIG welding was carried out using welding machines Fronius TPS-2700 and Fronius TPS-450. Surface of the metal before welding was dressed by scraper to $0.03-0.08 \mathrm{~mm}$ depth. Tilt angle of welding head made $10-15^{\circ}$, distance from torch nozzle to metal being welded was $8-12 \mathrm{~mm}$, arc length (distance between metal and wire end) made 3-5 $\mathrm{mm}$, argon consumption was $20 \mathrm{l} / \mathrm{min}$. Welding of the butt joints was carried out on removable backings from stainless steel with grooves for formation of weld root reinforcement of $2 \mathrm{~mm}$ width and $0.8 \mathrm{~mm}$ depth, that provided good reverse formation of the weld.

Geometry parameters of the welds (width $b$ and height $h$ of weld reinforcement on welded joint surface) were determined using macrosections. Geometry parameters of the weld root reinforcement virtually corresponded with the dimensions of forming grooves of the backings. Values of rate of energy input were calculated on formula $q_{\mathrm{i}}=K_{\mathrm{ef}} I_{\mathrm{w}} U_{\mathrm{a}} / v_{\mathrm{w}}, \mathrm{kJ} / \mathrm{cm}$, where $K_{\mathrm{ef}}$ is the efficient performance of the arc ( 0.72 for argon).

The calculations showed that, if the same depth of penetration of $2 \mathrm{~mm}$ thick metal is maintained, than 3 times increase of welding speed (for example, from 20 to $60 \mathrm{~m} / \mathrm{h}$ ) requires 1.5 times rise of current intensity and 1.15 times increase of arc voltage, but finally, results in 1.6 times reduction of rate of energy input of the welding process [10]. Such energy decrease reduces softening of welded joints from average

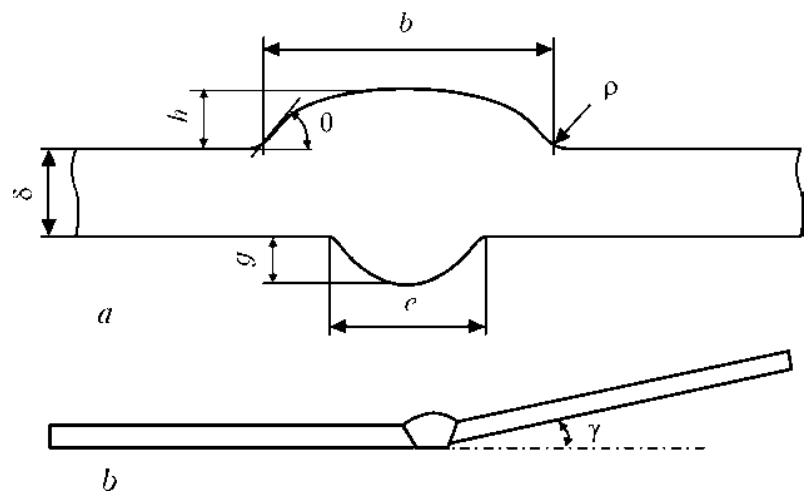

Figure 1. Parameters, determining SCF values of butt welded joints: $a-$ geometry parameters of joint; $b-$ angular distortion of butt joint and high strength aluminum alloys that promotes rise of their fatigue resistance.

It is well known that the main factors, determining fatigue resistance of structural material welded joints, are stresses concentration, caused by weld shape, and residual welding stresses (RWS), promoted by thermo-plastic strains, appearing during cooling $[5,9,11]$. In this connection, the values of stress concentration factor (SCF) were determined, the levels were measured and dependencies of RWS distribution in the butt welded joints of studied aluminum alloys were set.

Quantity determination of SCF requires data on real geometry of the welded joint. The maximum stresses in the butt joints act in zones of transition of weld surface to base metal at transverse loading in relation to weld and they depend mainly on such parameters as radius $\rho$ and angle $\theta$ of fillet surface (Figure 1, $a$ ). Among main geometry parameters of the butt welds, determining stress concentration, are also width $b$ and $e$, and height $h$ and $g$ of reinforcement from face and root of the weld. SCF depends also on value of angular distortion (Figure 1, b) in sheet aluminum alloy welded joints, for which angular distortion of welded sheets $\gamma$ is typical (angular displacement in welded joint zone, caused by bending of one welded plate relatively to another).

SCF values of the butt joints were determined by Stakanov-Korostylev-Rybin formula [12]

$$
\alpha_{\sigma}^{\prime}=1+\left[\frac{\rho}{\sin \theta}\left(\frac{2}{\delta}+\frac{4}{b}+\frac{0.8}{h}\right)\right]^{-0.5} .
$$

Area of expression (1) application covers the ranges of weld reinforcement size [13]: $\rho / \delta=$ $=0.01-0.10 ; h / \delta=0.1-0.2 ; \theta=15-30^{\circ} ; b / \delta=$ $=0.15-2.80$. SCF due to angular distortion were determined on formula of Colchen [14]

$$
K_{\gamma}=1+3.1 \frac{\sin \gamma}{\delta}
$$

where $\delta$ is the thickness of plates being welded.

Total SCF in the butt joint considering angular distortion was determined on formula

$$
\alpha_{\sigma}=\alpha_{\sigma}^{\prime} K_{\gamma} \text {. }
$$

It is found that angle $\gamma$ varies in the range of $2-5^{\circ}$ for all studied materials at $2 \mathrm{~mm}$ thickness of plates being welded, and corresponding SCF values due to angular distortion $K_{\gamma}$ made 1.04-1.14.

Profilometer-based method was selected for measurement of weld geometry parameters. Portable profilimeter, developed at the E.O. Paton Electric Welding Institute, and engineer microscope BMI-1, equipped with head having mechanical indicator and cone tip, were used in realizing of this method. The profiles of joint surfaces were designed based on measurement results 
Table 1. Geometry parameters of profiles of welds of butt PMIG-welded joints $(\delta=2 \mathrm{~mm})$

\begin{tabular}{||c|c|c|c|c|c|c|c|}
\hline \multirow{2}{*}{ Alloy } & $\begin{array}{c}\text { Side of joint } \\
\text { treatment }\end{array}$ & $\rho, \mathrm{mm}$ & $\theta, \mathrm{deg}$ & $b, \mathrm{~mm}$ & $h, \mathrm{~mm}$ & $\gamma_{\mathrm{av}}, \mathrm{deg}$ & 3 \\
\hline \multirow{2}{*}{ D16T } & Face & $0.39 / 0.11$ & $24 / 4$ & $5.33 / 0.15$ & $1.19 / 0.12$ & $1.66 / 0.21$ \\
\cline { 2 - 7 } & Root & $0.33 / 0.08$ & $29 / 2$ & $3.46 / 0.15$ & $1 / 0.15$ & $1.82 / 0.26$ \\
\hline \multirow{2}{*}{ AMg6 } & Face & $0.55 / 0.21$ & $35 / 9$ & $6.59 / 0.19$ & $1.34 / 0.16$ \\
\cline { 2 - 7 } & Root & $0.31 / 0.16$ & $34 / 13$ & $3.72 / 0.47$ & $1.10 / 0.18$ & $1.68 / 0.14$ \\
\hline \multirow{2}{*}{$6061-T 6$} & Face & $1.01 / 0.32$ & $28 / 3$ & $7.20 / 0.46$ & $1.78 / 0.48$ \\
\cline { 2 - 7 } & Root & $0.37 / 0.21$ & $51 / 10$ & $4.70 / 0.65$ & $1.37 / 0.21$ \\
\hline
\end{tabular}

Note. Here and in Table 2 numerator - average value; denominator - their root-mean-square deviation.

using computer processing. Table 1 shows the results of measurement of geometry parameters for typical profiles of studied aluminum alloy welded joints. Determined values of theoretical SCF lie in 1.61-1.68 range for face and 1.78-1.88 for weld root.

Measurements of RWS in studied alloy welded joints with the weld in midsection of the plate were carried out by non-destructive acoustic method [15]. Figure 2 shows dependence of maximum level of residual stresses on width of welded plates from 6061-T6 and AMg6 alloys, and Figure 3 represents distribution of the residual stresses in welded plate from AMg6 alloy of $600 \times$ $\times 600 \times 2 \mathrm{~mm}$ size, measured along butt weld at $2 \mathrm{~mm}$ distance from fusion zone. It can be seen that the maximum levels of values of the residual stresses longitudinal to weld achieve (0.4$0.5) \sigma_{0.2}$, and transverse residual stresses, acting, as a rule, along the direction of application of external loading are 2 times lower $((0.20-$ $0.25) \sigma_{0.2}$ ) in PMIG welding of sheet aluminum alloys $(\delta=2 \mathrm{~mm})$. Increase of width of plates being welded, virtually, provides for stabilizing of the maximum level of transverse residual stresses at width more than $200 \mathrm{~mm}$.

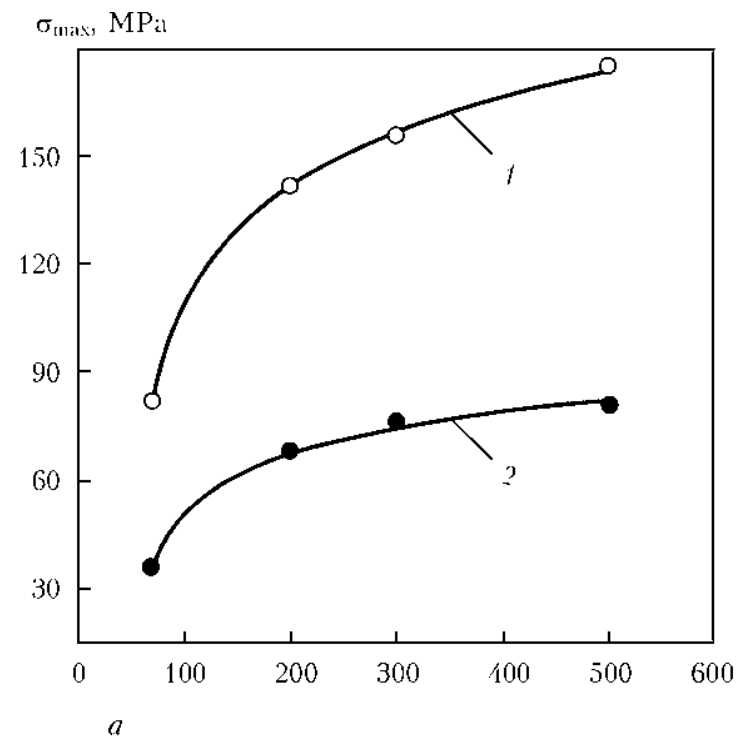

Effective parameters for treatment of butt welded joints using HFMP technology without breaking their geometry stability were determined at one-side peening of solid D16T alloy plate of $300 \times 100 \times 2 \mathrm{~mm}$ size. Standard peens of 2, 3 and $5 \mathrm{~mm}$ diameter were used for treatment of metal surface along the plate centerline, and angle $\gamma$ of plate plane deviation relatively to initial condition was measured at that. The experimental dependencies of change of deviation angle on linear speed of movement of operating tool along the treated surface were derived based on measurement results (Figure 4).

Treatment rate $4-10 \mathrm{~mm} / \mathrm{s}$ resulted in formation of maximum angle of plate lipping distortion equal $1-5^{\circ}$. The value of maximum deviation angle $\left(\gamma=5^{\circ}\right)$ due to one-side treatment of solid plate corresponds to the value of possible angle of residual strain of sheet PMIG-welded joints from studied aluminum alloys (see Figure 1,b). Therefore, recommended rate of joint treatment lied in $4-10 \mathrm{~mm} / \mathrm{s}$ range. Treatment of the joints with linear speed of operating tool movement $7-9 \mathrm{~mm} / \mathrm{s}$ is recommended in order to rise efficiency and achieve maximum reduction of SCF

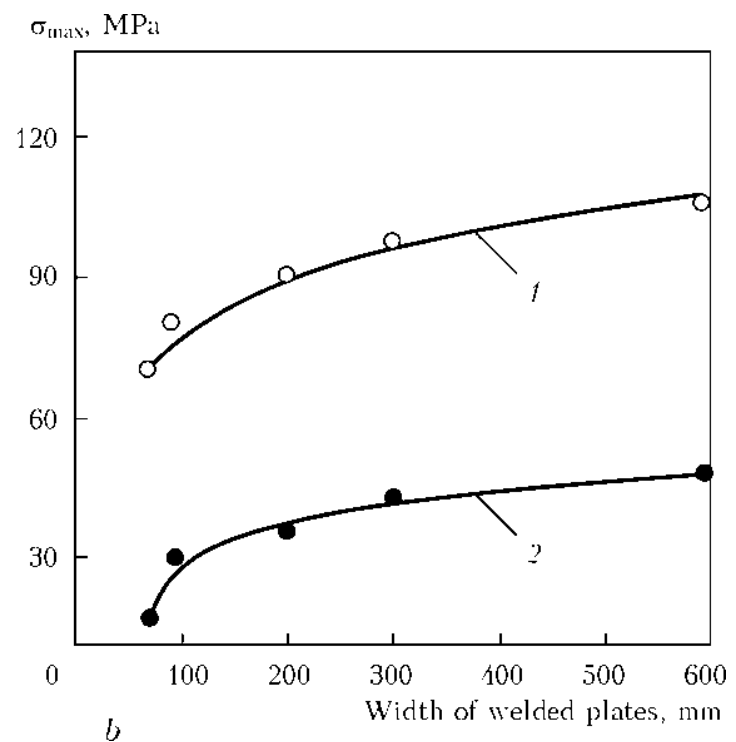

Figure 2. Dependence of maximum level of residual stresses on width of welded plates 2 mm thick: $a-$ alloy 6061 -T6 $\left(\sigma_{0.2}=262 \mathrm{MPa}\right) ; b-\operatorname{AMg} 6\left(\sigma_{0.2}=200 \mathrm{MPa}\right) ; 1-$ longitudinal $\sigma_{x} ; 2-$ transverse $\sigma_{y}$ stresses 


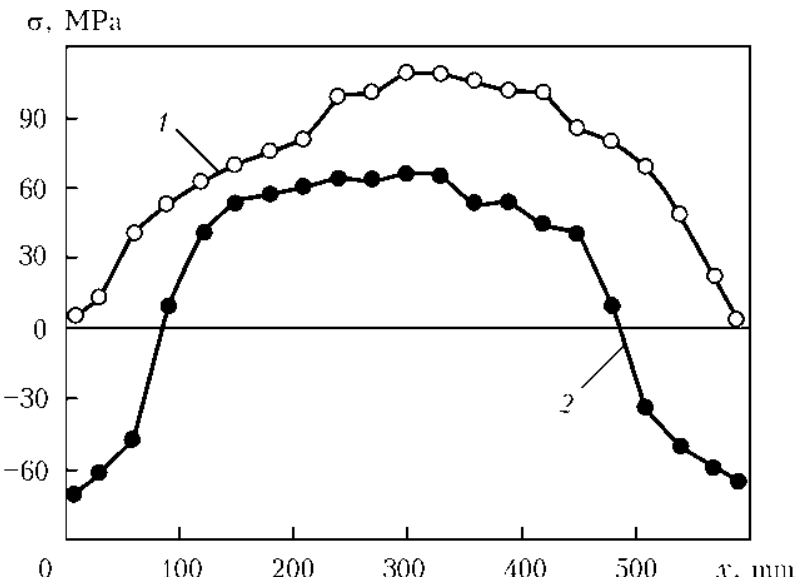

Figure 3. Distribution of residual stresses in welded plate of AMg6 alloy $600 \times 600 \times 2 \mathrm{~mm}$ in size, measured along weld at $2 \mathrm{~mm}$ distance from fusion zone: 1 - longitudinal $\sigma_{x} ; 2-$ transverse $\sigma_{y}$ stresses

in HFMP strengthening of sheet welded joints of aluminum alloys. Considering that transition radius of weld to base metal is lower from the root side than from the face one (see Table 1) $3 \mathrm{~mm}$ diameter peens were taken for strengthening of fusion zone from face side of the weld and that for root side had $2 \mathrm{~mm}$. In further investigations, all the specimens of butt joints were strengthened using HFMP with indicated effective parameters of treatment.

Calculations of theoretical SCF values in the welded joints after treatment were carried out,

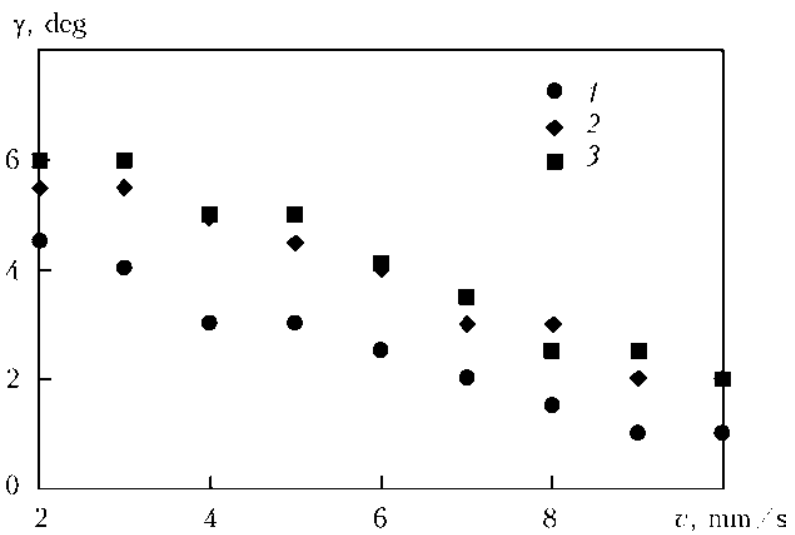

Figure 4. Dependence of angular distortion of $300 \times 100 \times$ $\times 2 \mathrm{~mm}$ size plate from alloy D16T at one-side peening of metal along plate centerline on linear speed of operating tool travel at HFMP: $1-d=2 ; 2-3 ; 3-5 \mathrm{~mm}$

and their comparison with corresponding SCF values of as-welded joints was performed. Peening of zones of weld to base metal transition is carried out in joint strengthening using HFMP that results in formation of cylindrical surfaces in form of grooves in this zone. Profile of the formed groove has radius which, as a rule, corresponds to radius of spherical surface of applied percussion peens. Geometry parameters of the weld profiles, necessary for SCF determination, were received using profilograms of fusion zone of the strengthened welded joints. Table 2 shows the SCF values of welded joints from studied
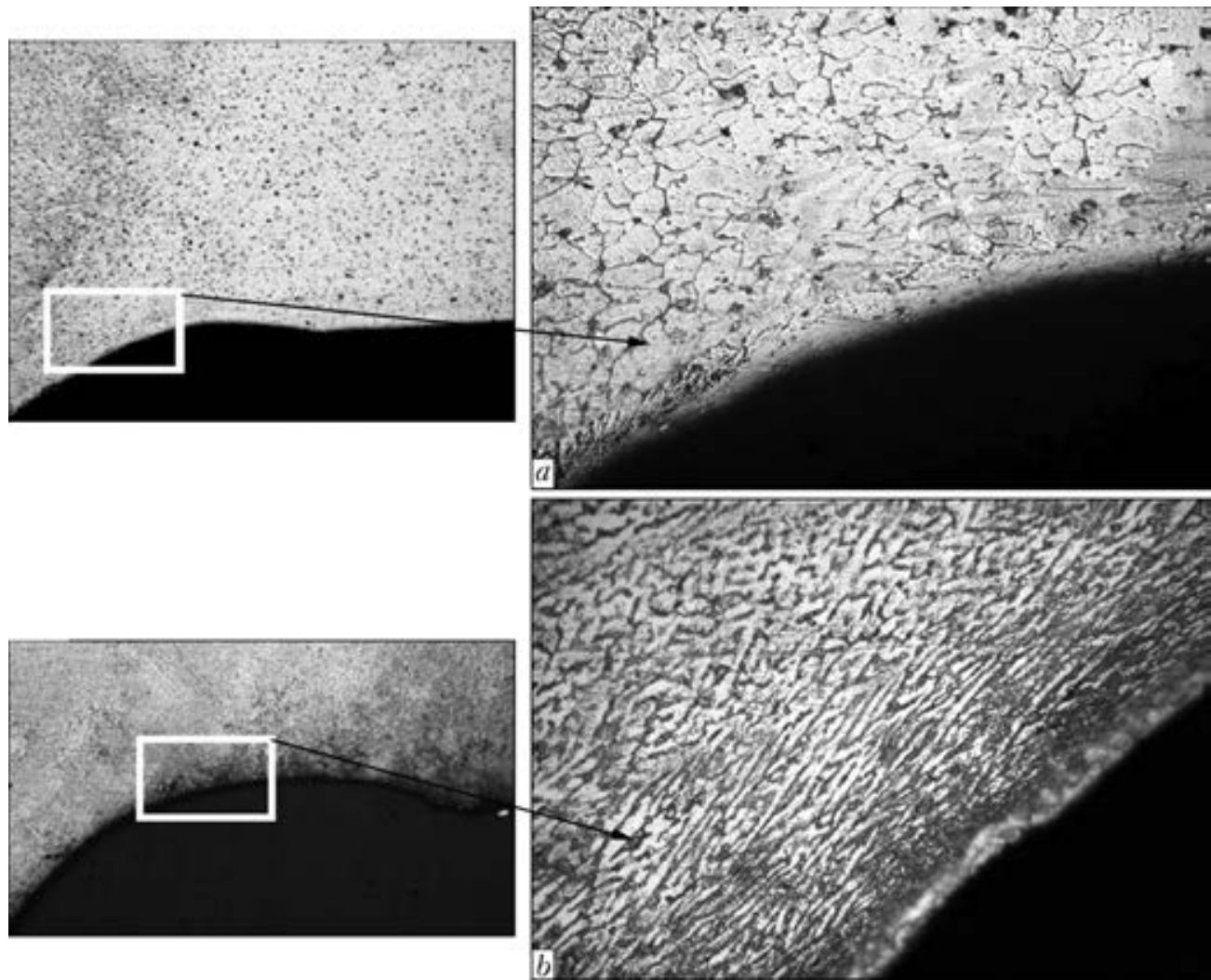

Figure 5. Microstructure of subsurface layer of weld to base metal transition zone from root side of D16T $(a-\times 500)$ and AMg6 alloy $(b-\times 400)$ after HFMP (etched) 
Table 2. Values of SCF of butt PMIG-welded joints before strengthening $\alpha_{\sigma}$ and after HFMP $\alpha_{\sigma}^{\text {str }}$

\begin{tabular}{|c|c|c|c|c||}
\hline \multirow{2}{*}{ Alloy } & $\begin{array}{c}\text { Side of joint } \\
\text { treatment }\end{array}$ & $\alpha_{\sigma}$ & $\alpha_{\sigma}^{\text {str }}$ & $\alpha_{\sigma} / \alpha_{\sigma}^{\text {str }}$ \\
\hline \multirow{2}{*}{ AMg6 } & Face & $1.68 / 0.14$ & $1.13 / 0.07$ & 1.49 \\
\cline { 2 - 5 } & Root & $1.78 / 0.48$ & $1.21 / 0.06$ & 1.47 \\
\hline \multirow{2}{*}{$6061-\mathrm{T} 6$} & Face & $1.61 / 0.21$ & $1.19 / 0.12$ & 1.35 \\
\cline { 2 - 5 } & Root & $1.88 / 0.27$ & $1.27 / 0.11$ & 1.48 \\
\hline \multirow{2}{*}{ D16T } & Face & $1.66 / 0.21$ & $1.16 / 0.10$ & 1.43 \\
\cline { 2 - 5 } & Root & $1.82 / 0.26$ & $1.13 / 0.11$ & 1.39 \\
\hline
\end{tabular}

alloys after HFMP in accordance with determined parameters of treatment. It can be seen from the Table that reduction of average values of SCF in strengthened joints can make 1.5 times at effective parameters of strenghtening. Such reduction of SCF (to $50 \%$ ) in the strengthened joints is the important factor, promoting increase of their fatigue resistance.

The metallographic investigations of treated surface were carried out at up to $\times 500$ magnification in zone of weld to base metal transition for the welded joints from studied D16T and AMg6 alloys. The results of structure examination of strengthened surface layer showed absence of cracks, cleavages and delamination in this layer (Figure 5).

Change of grain structure at up to $250 \mu \mathrm{m}$ depth is observed in subsurface layer of the joint after HFMP of the fusion zone. At that, deformed grains are elongated in the planes parallel to treated surface tangent line. Measurement of microhardness of weld, HAZ and base metal of AMg6 welded joint in as-welded condition and after HFMP of these zones showed that PSD resulted in $65-75 \%$ rise of hardness of weld metal at 50-60 $\mu \mathrm{m}$ depth, that for HAZ made 16-25\% and $22 \%$ for base metal (Figure 6 ).

The change of metal structure and rise of hardness in the subsurface layers after HFMP show that present structural factor and strain hardening, in addition to reduction of SCF value, can have positive effect on increase of joint fatigue resistance.

Strain-gauging was used for measurements of the residual stresses in AMg5 alloy welded plates of $300 \times 300 \times 2 \mathrm{~mm}$ size in as-welded condition and after HFMP of the fusion zone.

Figure 7 represents received measurement data of RWS along the butt weld at $3 \mathrm{~mm}$ distance from the fusion zone for as-welded joints and joints after strengthening. As can be seen from presented diagrams, the transverse residual stresses, acting of which corresponds with direction of applied external loads, causing stress concentration in the fusion zone, are insignificant. Their maximum values in middle part of the weld makes only $40 \mathrm{MPa}$ and after strengthening these stresses reduce by 23-

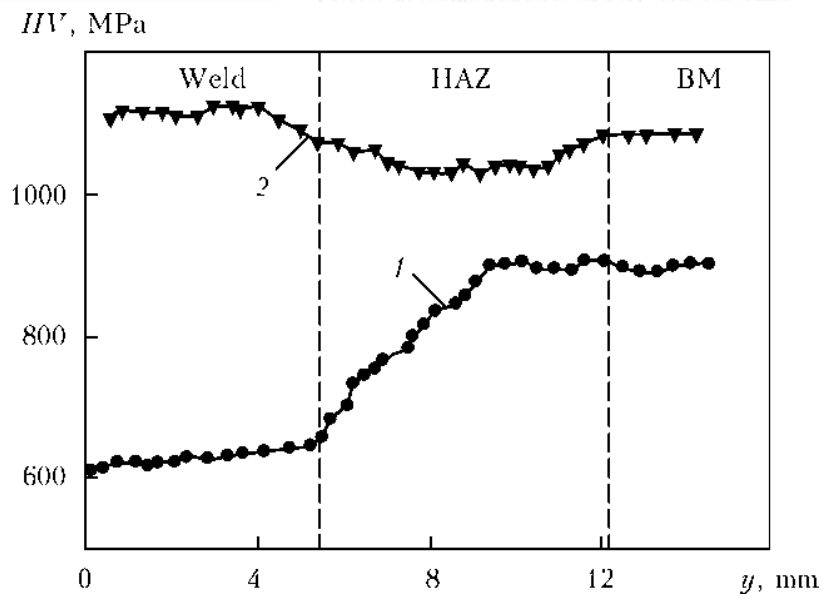

Figure 6. Distribution of microhardness in AMg6 alloy welded joint in direction normal to weld at 50-60 $\mu \mathrm{m}$ depth (beginning of coordinates - in weld center): 1 - microhardness before; 2 - after HFMP

$30 \%$ more. Such stress levels have no significant effect on joint fatigue resistance.

Current servohydraulic machine MTS 318.25 with maximum loading $250 \mathrm{kN}$ was used for fatigue testing of the specimens from base metal and welded joints. Corset type specimens ( $\mathrm{Fi}-$ gure 8) were tested at set constant values of stress
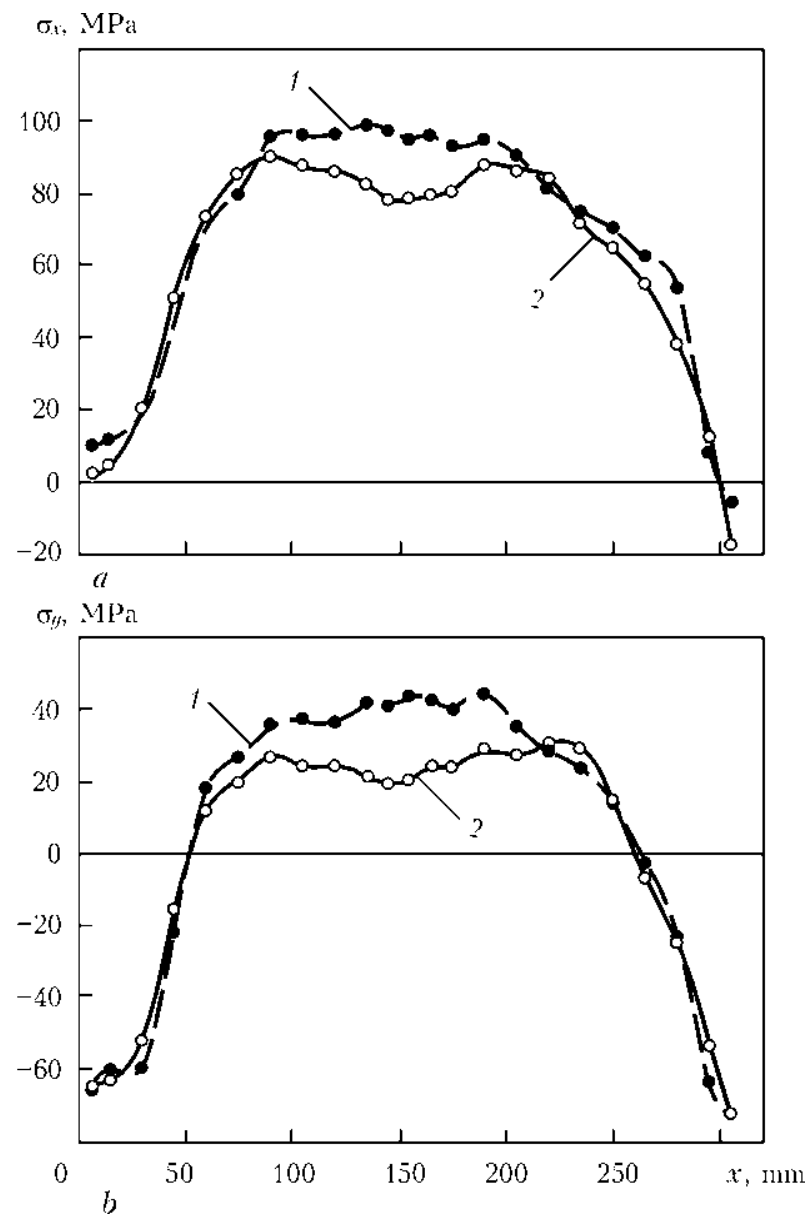

Figure 7. Distribution of residual stresses in AMg6 alloy welded plates of $300 \times 300 \times 2 \mathrm{~mm}$ size before (1) and after (2) HFMP, measured in sections parallel to weld at $3 \mathrm{~mm}$ distance from weld: $a-$ longitudinal $\sigma_{x} ; b-$ transverse $\sigma_{y}$ stresses 


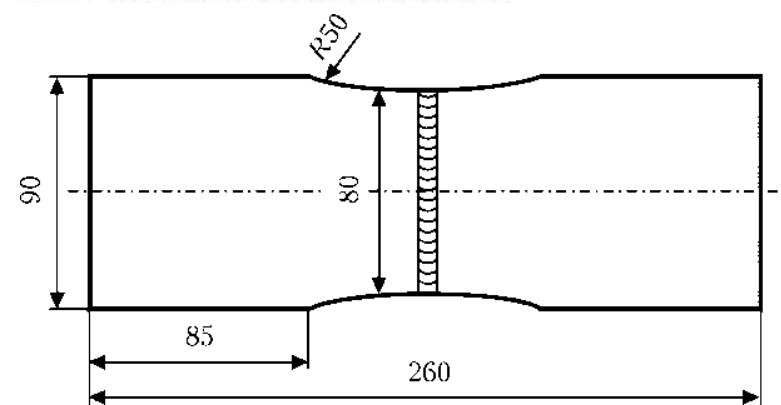

Figure 8. Shape and geometry dimensions of welded specimens for fatigue tests

range, corresponding to range of fatigue life of $5 \cdot 10^{4}-2 \cdot 10^{6}$ cycles of stress alternation at constant asymmetry of cycle to complete fracture. Respective fatigue curve (line of regression of experimental data) was plotted in $2 \sigma_{a}-\lg N$ coordinates based on the results of carried fatigue tests for each series of the specimens using set experimental data of restricted fatigue limits.

Figure 9 represents experimental data, received on results of fatigue tests of four series of specimens of AMg6 alloy welded joints. For asymmetry of stress cycle $R_{\sigma}=0$, the restricted fatigue limit of HFMP-strengthened fusion zones of the butt joints on the basis of $2 \cdot 10^{6}$ cycles rised by $27 \%$ in comparison with the fatigue limit of as-welded joints. At that, fatigue life of the joints increases 4 times. Peening efficiency somewhat
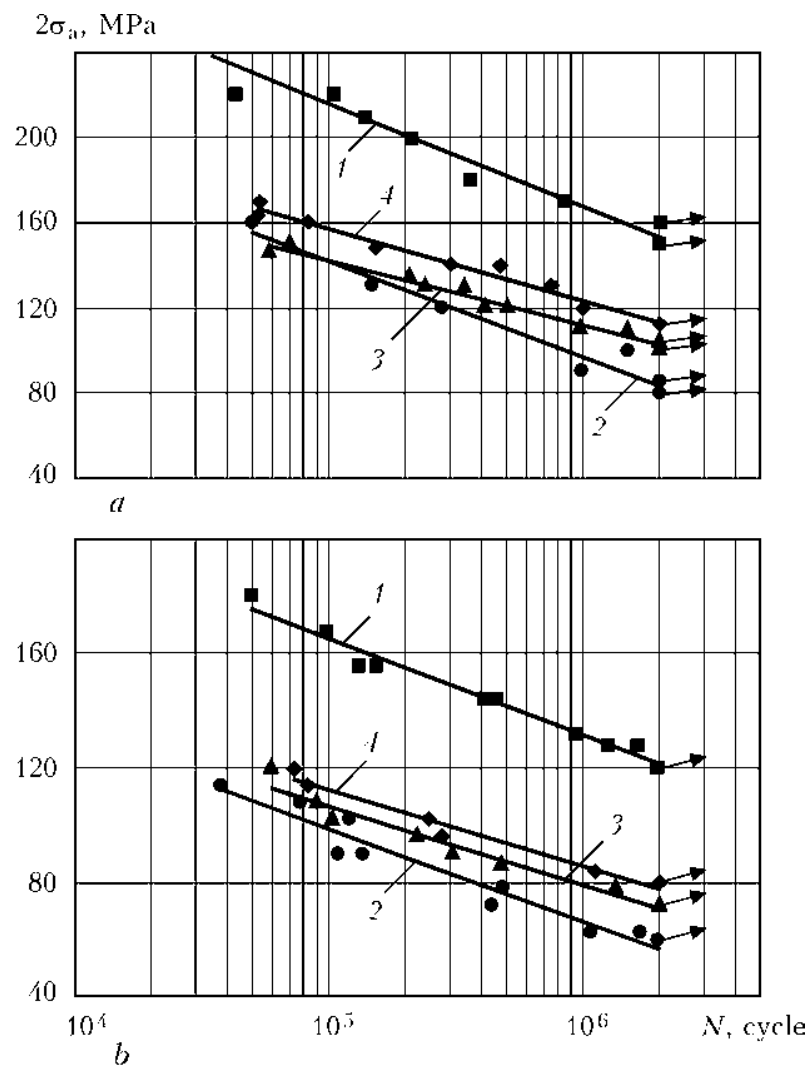

Figure 9. Fatigue curves for AMg6 alloy welded joints $2 \mathrm{~mm}$ thick corresponding to asymmetry of stress cycle $R_{\sigma}=0$ ( $a$ ) and $0.4(b)$ : 1 - base metal; 2 - as-welded; 3 - HFMPstrengthened joints; 4 - joints with mechanical dressing of weld reinforcement

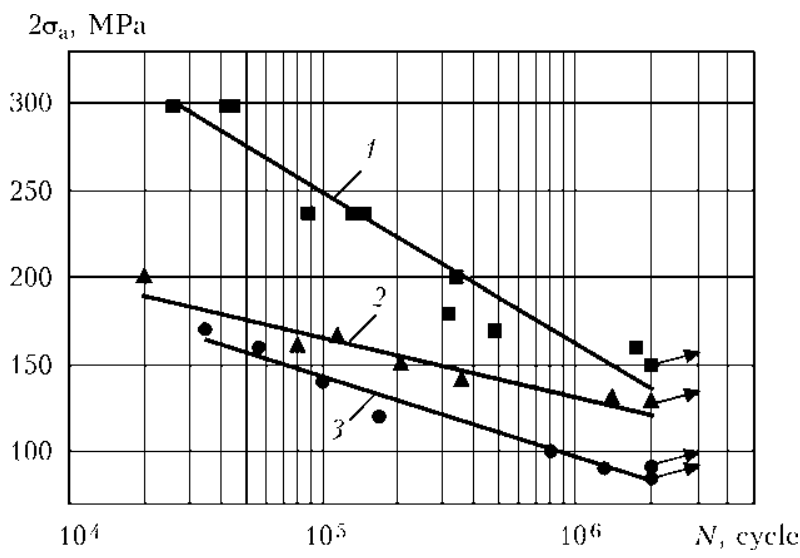

Figure 10. Fatigue curves for 6061-T6 alloy welded joints $2 \mathrm{~mm}$ thick corresponding to asymmetry of stress cycle $R_{\sigma}=$ $=0.1: 1-$ base metal; $2-$ as-welded; $3-$ HFMPstrengthened joints

reduces at increase of stress cycle asymmetry. Thus, the restricted fatigue limit on the basis of $2 \cdot 10^{6}$ cycles of stress alternation rised by $21 \%$ at $R_{\sigma}=0.4$. Strengthening efficiency reduces at rise of amplitude of applied stresses and HFMP treatment has, virtually, no effect for zero-to-compression $\left(R_{\sigma}=0\right)$ as well as repeated $\left(R_{\sigma}=0.4\right)$ alternate loading already in the area of life below $10^{5}$ cycles. Received experimental data on fatigue resistance of HFMP-strengthened welded joints rise in high-cycle area to values close to that in the joints with removed weld reinforcement. This
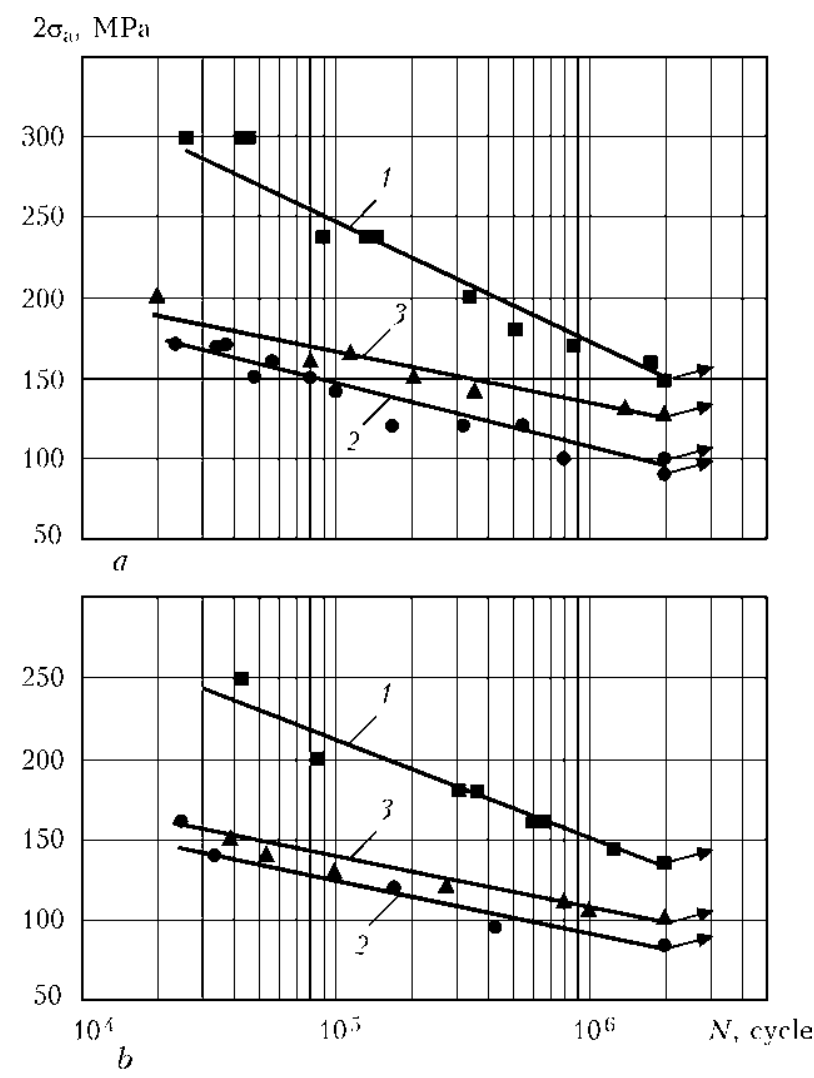

Figure 11. Fatigue curves for D16T alloy butt welded joints $2 \mathrm{~mm}$ thick corresponding to asymmetry of stress cycle $R_{\sigma}=$ $=0.1(a)$ and 0.4 (b): 1 - base metal; 2 - as-welded; 3 - HFMP-strengthened joints 
indicates the prospects of application of low-cost HFMP instead of laborious generally accepted mechanical treatment.

Increase of fatigue resistance of HFMPstrengthened fusion zones of butt joints from 6061-T6 heat-hardenable alloy is observed in all range of life of $5 \cdot 10^{5}-2 \cdot 10^{6}$ cycles of stress alternation (Figure 10). At that, their fatigue life rises up to 7 times in comparison with initial as-welded condition, and the restricted fatigue limit on the basis of $2 \cdot 10^{6}$ cycles has increased by $40 \%$.

The restricted fatigue limit of butt welded joint from high-strength aluminum alloy D16T on the basis of $2 \cdot 10^{6}$ cycles of stress alternation with $R_{\sigma}=0.1$ asymmetry rised after HFMP of zone of weld to base metal transition by $30 \%$ in comparison with as-welded joints, and the fatigue life of the joints increased 5 times (Figure 11, a). Similar to AMg6 alloy, rise of stress cycle asymmetry decreases efficiency of HFMP strengthening. Thus, the restricted fatigue limit on the basis of $2 \cdot 10^{6}$ cycles increases only by $13 \%$ at $R_{\sigma}=0.4$ and the fatigue life at that rises 3 times (Figure 11, b).

Received results shows that HFMP strengthening of the fusion zones of sheet butt welded joints of aluminum alloys AMg6, D16T and 6061T6 can significantly rise their fatigue life.

\section{Conclusions}

1. Weld parameters for butt welded joints from D16T, AMg6 and 6061-T6 alloys of $2 \mathrm{~mm}$ thickness were determined and evaluated in as -welded and after HFMP strengthening condition. These joints were made for the first time using optimized PMIG welding technology.

2. Nature of distribution of the residual stresses was investigated for PMIG welding of sheet $(\delta=$ $=2 \mathrm{~mm}$ ) aluminum alloys of average and high strength. It is shown that the maximum values of residual tensile stresses longitudinal to weld make $(0.4-0.5) \sigma_{0.2}$, and transverse residual stresses, acting, as a rule, along the direction of external loading, are 2 times lower $\left((0.20-0.25) \sigma_{0.2}\right)$.

3. Effective parameters of HFMP strengthening of sheet welded joints from aluminum alloys of average and high strength were determined. Range of linear speed of operating tool movement during HFMP makes 7-9 mm/s, peen diameter is 3 and $2 \mathrm{~mm}$ for face and root sides of the weld, respectively. Using of such parameters provides for PSD of metal in treated zone of the joints without deviation of their geometry at $0.23-$ $0.28 \mathrm{~mm}$ depth. Application of HFMP of fusion zone of the butt welded joints results in $20-50 \%$ reduction of the transverse residual tensile stresses near weld. At that, SCF values in zones of stress concentrators of the butt joints reduce
1.35-1.49 times and its absolute values lie in 1.13-1.27 range for studied alloys.

4. Efficiency of HFMP strengthening of the fusion zones for rising of fatigue life in sheet butt joints from aluminum alloys was experimentally verified. It is determined that life of strengthened D16T alloy joints in high-cycle area of $5 \cdot 10^{5}$ $2 \cdot 10^{6}$ cycles of stress alternation shows 5 times rise and that for AMg6 alloy is 4 times and in the case of 6061-T6 alloy it makes 7 times in comparison with as-welded condition.

5. It is experimentally determined that the fatigue limit on the basis of $2 \cdot 10^{6}$ cycles of stress alternation of the sheet butt joints from aluminum alloy AMg6, strengthened using HFMP, achieves the level of fatigue limit of the joints with removed weld reinforcements that $20 \%$ higher of fatigue limit of the untreated joints. Therefore, HFMP with set parameters can be recommended for strengthening of such joints instead of more expensive and technologically complex mechanical dressing of the weld.

1. Elagin, V.I. (2009) Structural nanoalloys alloys on aluminium base. Tsvet. Metally, 6, 103-111.

2. Filatov, Yu.A. (1996) Wrought alloys based on Al$\mathrm{Mg}-\mathrm{Sc}$ system. Metallovedenie $i$ Term. Obrab. Metallov, 6, 33-36.

3. Fridlyander, I.N., Beletsky, V.M., Krivov, G.A. (2000) Aluminium alloys in aircraft structures. Tekhnologich. Sistemy, 1(3), 5-17.

4. Ishchenko, A.Ya., Labur, T.M., Bernadsky, V.N. et al. (2006) Aluminium and its alloys in current welded structures. Kiev: Ekotekhnologiva.

5. Ishchenko, A.Ya., Labur, T.M. (2013) Welding of current structures from aluminium alloys. Kiev: Naukova Dumka.

6. Mashin, V.S., Pavshuk, V.M., Dovbishchenko, I.V. et al. (1991) 'Influence of pulsed-arc welding conditions of aluminium ADO on shape and porosity of welds. Avtomatich. Svarka, 4, 57-60.

7. Shonin, V.A., Mashin, V.S., Vojtenko, O.V. et al. (2003) Improvement of fatigue resistance of tee welded joints in sheet aluminium alloy AMg6. The Paton Welding J., 7, 7-10.

8. Ostrovsky, O.S., Gudko, A.V., Kudryashyov, O.N. et al. (1992) Consumable-electrode pulsed-arc welding of large-sized structures of aluminium alloys. Svaroshn. Proizvodstvo, 10, 7-9.

9. Lobanov, L.M., Kirian, V.I., Knysh, V.V. et al. (2006) Improvement of fatigue resistance of welded joints in metal structures by high-frequency mechanical peening (Review). The Paton Welding J., 9, 2-8.

10. Mashin, V.S., Pashulya, M.P., Shonin, V.A. et al. (2010) Consumable electrode pulsed argon-arc welding of sheet aluminium alloys. Ibid., 5, 38-41.

11. Trufyakov, V.I. (1990) Strength of welded joints under alternative loads. Kiev: Naukova Dumka.

12. Stakanov, V.I., Kostylyov, V.I., Rybin, Yu.K. (1987) Stress concentration in butt welded joints. Avtomatich. Svarka, 11, 19-23.

13. Karkhin, V.A., Kopelman, L.A. (1976) Stress concentration in butt joints. Svarochn. Proizvodstvo, 2, 6-7.

14. Colchen, D. (2000) Application des calculs aux elements finis pour definer et valider des modeles analytiques de calcul de contrainte sur un assemblage bout a bout en alliage d'aluminium. Soudage et Techniques Connexes, $54(\mathbf{3} / \mathbf{4}), 3-16$.

15. Gushcha, O.I., Smilenko, V.N., Kot, V.G. et al. (2009) Testing of stresses based on application of subsurface acoustic waves. Tekhn. Diagnostika $i$ Nerazrush. Kontrol, 1, 11-13. 